\title{
Effect of Various Depth of Pupation On Adult Emergence of Interspecific Hybrid of Bactrocera Carambolae And Bactrocera Dorsalis
}

\author{
Agus Susanto ( $\square$ asusanto@unpad.ac.id ) \\ Universitas Padjadjaran, Sumedang \\ Maura Gita Faradilla \\ Universitas Padjadjaran, Sumedang \\ Yayan Sumekar \\ Universitas Padjadjaran, Sumedang \\ Dwi Harya Yudistira \\ Universitas Padjadjaran, Sumedang \\ Wayan Murdita \\ Pest Forecast Institute, Jatisari \\ Agus Dana Permana \\ Institut Teknologi Bandung, West Java \\ Luciana Djaya \\ Universitas Padjadjaran \\ Syifa Nabilah Subakti Putri \\ Universitas Padjadjaran
}

\section{Research Article}

Keywords: Fruit fly, imago movement, Interspecific hybrid, pupation, soil depth

Posted Date: November 12th, 2021

DOI: https://doi.org/10.21203/rs.3.rs-1049439/v1

License: (c) (1) This work is licensed under a Creative Commons Attribution 4.0 International License. Read Full License

Version of Record: A version of this preprint was published at Scientific Reports on March 10th, 2022. See the published version at https://doi.org/10.1038/s41598-022-08295-w. 


\section{Abstract}

Bactrocera carambolae and $B$. dorsalis are genetically related in that both have the same type of host plant, and hybridization between $B$. carambolae and $B$. dorsalis may occur naturally. The depth of the pupation is one of the important factors in adult emergence rate. This objective of this study was to estimate the depth of the pupation that can suppress the emergence of adult interspecific hybrids of $B$. carambolae and $B$. dorsalis. The experiments consisting of seven depths of pupation treatments $(4 \mathrm{~cm}, 10 \mathrm{~cm}, 20 \mathrm{~cm}, 30 \mathrm{~cm}, 40$ $\mathrm{cm}, 50 \mathrm{~cm}$, and $60 \mathrm{~cm}$ ) with four replications. The results showed that $91 \%$ of the adult interspecific hybrids of $B$. carambolae and $B$. dorsalis emerged successfully at $4 \mathrm{~cm}$ depth of pupation. Furthermore, the emergence rate was found to decrease with the increase in pupation depth. Soil depths ranging between 50 and $60 \mathrm{~cm}$ can suppress the emergence rate of adult interspecific hybrids of $B$. carambolae and $B$. dorsalis.

\section{Introduction}

Bactrocera carambolae and $B$. dorsalis are the most destructive pests for various vegetables and fruits (Clarke, 2019), and both species are members of the $B$. dorsalis complex (Drew \& Romig, 2013). These species can be distinguished based on the morphological pattern of adult wings, dark spots on the foreleg femora, and abdominal patterns (Drew \& Romig, 2013). Morphological characteristics between these species were detected from wild fruit flies trapped with methyl eugenol in Indonesia and Malaysia (Kago et al., 2012; Juma et al., 2014). A study by Wee and Tan (2005) shows that interspecific mating in B. dorsalis can produce fertile offspring.

The mating compatibility between B. carambolae and B. dorsalis is about 40\% (Schutze et al., 2013). The damage level of interspecific hybrid $B$. dorsalis and $B$. carambolae is unknown. In general, fruit flies can cause damage both quantitatively and qualitatively. Quantitative damage occurs due to fruit fly attacks, which can reduce fruit yield.

Qualitative damage occurs because the fruits are damaged in certain parts or in all parts of the fruit (Heriza et al., 2013). For example, the yield loss of bitter gourd due to B. cucurbitae attack was $36.24 \%$ (Pilania et al., 2021). Asmare and Hassen's (2018) study found that the damage by fruit flies could reach up to $33.3-66.7 \%$ for guava, and 29.2 - 44.4\% for sweet orange in Ethiopia. It is very possible that interspecific hybridization between species plays an important role in the formation, spread, and impact of invasive populations (Hill et al., 2016).

Metamorphosis is found among many insects in nature, including the Bactrocera species. Bactrocera metamorphosis is holometabolous, as it consists of egg, larvae, pupa and imago (Plant Health Australia, 2016). The development of techniques and research on fruit fly control is mostly focused on adults, for example the use of methyl eugenol (Bajaj \& Singh, 2020), modified traps (Susanto et al., 2020), essence lure (Susanto et al., 2019), and botanical pesticides.

However, there is little discussion on the possibility of Bactrocera pupae control. Some researchers mention the effectiveness of fruit fly control by targeting late instar larvae or pupae (El-Gendy \& Abdallah, 2019). The depth of the media can affect the development of fruit fly pupae and affects the effort of fruit flies to emerge 
to the surface, as the deeper the pupation of the fruit fly, the higher the effort required. Pupation depth is also related to garden sanitation, in the form of preventive control by burying fruit infested with fruit flies (Hasyim et al., 2014).

Sanitation is the key for suppressing the population of fruit flies and the function of field sanitation is to break the life cycle of fruit flies. It was previously observed that $C$. capitata pupae were able to emerge as imagoes at a soil depth of $20 \mathrm{~cm}$ (Djamila et al., 2007), while B. zonata were able to grow up to a depth of 30 $\mathrm{cm}$. Hou et al. (2006) suggested that $B$. dorsalis pupae can grow in soil depths under $4 \mathrm{~cm}$ with a survival rate of up to $90 \%$ at soil moistures of $10-60 \%$. pupation position can affect the success of parasitization from parasitoids to the effectiveness of biocontrol agents. Okuyama's study (2019) suggested that the probability of parasitism succession on pupa decreases as the pupation depth increases.

An unfavorable environment can interfere with pupal development in fruit flies. This information can be useful as a recommendation for managing soil conditions. The type of soil and water in this case plays an important role in the emergence of adults. There was no adult emergence in $B$. minax when the soil was immersed at $0 \%$ and a maximum of 15\% (Li et al., 2019). Hou et al. (2006) suggested that soil moisture affected the development time of $B$. dorsalis. It is important to study the behavior and ecology of pupae in Bactrocera to determine the application of fruit fly control at the pupal stage. Klungness (2005) suggested that immersing the fruit as deep as $30 \mathrm{~cm}$ suppressed the emergence of $B$. cucurbitae. Moreover, no adult emergence was found at a depth of $46 \mathrm{~cm}$. This is because soil density and porosity affect the appearance of imagoes. This study aims to determine the effect of soil depth on the emergence of imagoes from the interspecific hybrids $B$. dorsalis and $B$. carambolae.

\section{Materials And Methods}

\section{Insect rearing}

Individual pupae of Bactrocera dorsalis and Bactrocera carambolae were obtained from the Pest Forecast Institute, Jatisari. The colony was raised until they reached the imago stage in the Pest Laboratory of the Faculty of Agriculture, Universitas Padjadjaran, Indonesia. The adult fruit flies were kept in a mesh-covered cage sized $50 \mathrm{~cm} \times 50 \mathrm{~cm}$ x $50 \mathrm{~cm}$ and maintained at room temperature $\left(25-28^{\circ} \mathrm{C}\right)$ with a 12:12 (light:dark) photoperiod. They were fed sugar cubes, autolyzed yeast (AY-65), and water. After two weeks out of the pupae, the male $B$. dorsalis mated with adult female of $B$. carambolae.

F1 hybrid eggs were harvested using an egging device made of plastic cups with oviposit holes (diameter \pm $0.1 \mathrm{~mm}$ ). The egging device was filled with kweni fruit juice and covered with a plastic wrap on top of it. The adult female laid their eggs into the oviposit hole and the eggs were collected after two hours. The eggs were transferred to tissue paper and placed in a plastic bowl filled with feed. The feed was made from carrot puree (300 grams), mixed with yeast (15 grams), nipagin (1.5 grams), distilled water (300 ml) and propionic acid (4 $\mathrm{ml})$. The plastic bowl was then transferred to a container box already containing sawdust as the pupation medium. F1 hybrid pupae were then collected and used for the experiment.

\section{Pupation medium}


Soil was collected from Mango Garden, Ujung Jaya Village, Tomo Sub District, Sumedang Regency. Soil samples were collected from five locations with a depth of $0-20 \mathrm{~cm}$ and were then composed. Before use, the soil was sieved through a $1.5 \mathrm{~mm}$ mess and sterilized using an autoclave ( $1 \mathrm{~atm})$ for 15 minutes at $120^{\circ} \mathrm{C}$. Soil texture was analyzed as sand (7.52\%), clay (56.54\%), and silt (35.94\%). Besides that, the water capacity of the soil was $45.27 \%$, the porosity was $57.74 \%$, and the permeability was $0.29 \mathrm{~cm} /$ hour.

\section{Effect of various depths of pupation on adult emergence}

F1 hybrid pupae were collected after two days of formation. Seven various depths were tested for their ability on adult emergence. The treatment consisted of depths of 4, 10, 20, 30, 40, 50 and $60 \mathrm{~cm}$ and was repeated four times. Each treatment used 25 pupae with ages of about 1-2 days after formation. Experiments were carried out using mica plastic, which was formed in a tube with a diameter of $4.5 \mathrm{~cm}$ with a height of 30,60 and $70 \mathrm{~cm}$. The mica tube was filled with $1 \mathrm{~cm}$ of soil before the pupae were placed, then the pupae were covered with soil in accordance with each treatment. The top of the tube was covered with mesh to prevent adult fruit flies from escaping. After 7 days, the pupae's conditions in each treatment were checked daily until 14 days after the treatment. The number of adults that emerged and their behavior were recorded.

\section{Data analysis}

The number of emerged adults from each depth level was calculated into percentages. Abnormal imagoes were compared with normal imago in each treatment. The results were analyzed and the morphological condition of each imago was observed. The data were analyzed using the statistical software R studio version 4.1.0 for Kruskal-Wallis (non-parametric) followed by a multiple comparison test (Bonferroni) to compare the differences between various depths at the $a=0.05$ level.

\section{Results And Discussion}

Effect of various depth on interspecific hybrid Bactrocera dorsalis $\Downarrow$ and Bactrocera carambolae $\otimes$ adult emergence

The depth of pupation significantly affected the adults of interspecific hybrid $B$. dorsalis and $B$. carambolae emergence (Fig. 1). The highest emergence of interspecific $B$. dorsalis and $B$. carambolae hybrids occurred in the control treatment $(4 \mathrm{~cm})$ and at depth of $10 \mathrm{~cm}$ where the percentages of occurrence were $91 \pm 5.03 \%$ and $83 \pm 3.83 \%$, respectively (Fig. 1). This result indicates that the emergence rates of pupae from interspecific hybrids $B$. carambolae and $B$. dorsalis were higher than those of female parents. Amaral et al. (2021) found that the $B$. carambolae emergence rate was $89 \%$ at depths of around $0-4 \mathrm{~cm}$. Most of the pupae from the $B$. dorsalis of male parents survived within the $4 \mathrm{~cm}$ depth.

Surprisingly, some interspecific hybrid pupae of $B$. dorsalis and $B$. carambolae were able to emerge at a depth of $60 \mathrm{~cm}$ and other pupae survived even though during the experiment they did not grow into imago or the imago became abnormal (Fig. 1, Table 1) and significantly difference with $4 \mathrm{~cm}$ and $10 \mathrm{~cm}$ depth $\left(X^{2}=26.47\right.$, $d f=6, p=0.0001)$. It was deeper compared with the appearance of peach fruit fly imago which was appear up to a depth of $40 \mathrm{~cm}$ (Darwish et al., 2014). The control treatment showed that not all the pupae appeared, because some died during the experiment. 
Based on observation, some pupae were found dead in each treatment, but the percentages are low. Damaged or dead pupae showed several symptoms of a blackish brown color. Dead pupae in each treatment, in this case, did not show a significant difference. The pupae used in each treatment were uniform and in good condition. Unlike the case of dead pupae, there were variations in the number of imagoes that did not appear at every pupation depth. With every increase in pupation depth, the number of imagoes that did not appear also increased (Fig. 2).

The average rate of the emergence of hybrid imagoes began to decrease at a depth of $20 \mathrm{~cm}$ and continued to decrease until a depth of $60 \mathrm{~cm}$. The decrease in the rate of imago appearance may be due to the imagoes' difficulty to appear along with the increase in pupation depth. This relates to the energy required for the imagoes to reach the surface of the media. It can be seen in Table 1 that at a depth of $20 \mathrm{~cm}$ the rate of imago emergence can be reduced, as there is a significant difference when compared to the control group.

The appearance of imagoes at a depth of $20 \mathrm{~cm}$, although different from the control group, still has a rate of appearance of over $50 \%$, which is $59 \pm 9.45 \%$. Unlike the cases with depths of 30 and $40 \mathrm{~cm}$, the average appearance of interspecific hybrid imagoes was only $30 \pm 7.66$ and $21 \pm 7.57 \%$, respectively. The rate of the emergence of hybrid imagoes at this depth was relatively low, as the rate of imagoes that were unable to surface and died was over $50 \%$. This result is the same as that of B. cucurbitae that was unable to emerge at a depth of $46 \mathrm{~cm}$. The imagoes' difficulty to emerge to the surface of the media at depths of 50 and $60 \mathrm{~cm}$ was due to the insufficient energy possessed by the imagoes to reach the surface (Klungness, 2005).

\section{Effect of pupation depth on imago of interspecific hybrid $B$. dorsalis and B. carambolae morphology}

The morphology of a young imago that just emerged from the pupa is characterized as having a pale yellowish color, wings that are still wrinkled, an abdominal pattern that has not yet been formed, and a body that is longer, before it matures into a normal imago. The normal imago shows patterns on the wings and abdomen, which are distinguishing characteristics between fruit fly species (Fig. 3). Disruption of the pupa can cause some imagoes to be abnormal.

Interspecific hybrids of $B$. dorsalis and $B$. carambolae imagoes that were abnormal or defective were found at several pupation depths (Table 1). But abnormal imagoes were not significantly different among all treatment $\left(X^{2}=10.66, d f=6, p=0.09\right)$. Surface-appearing imagoes and defects were found many at depths of $30 \mathrm{~cm}$ to $60 \mathrm{~cm}$. In general, pupa abnormality was found on the wings. The wings' growth was imperfect, appearing to shrink or not develop. This is because, when the imagoes tried to reach the surface of the ground, it is suspected that the imagoes had developed before reaching the surface of the medium (Figure 4). Fruit flies take time to grow their wings to perfection. The time required for imagoes to become normal fruit fly imagoes is 25-35 minutes (Mir et al., 2014). 
Table 1

Effect of pupation depth on imago of interspecific hybrid B. carambolae $\nabla$ and $B$. dorsalis $\nabla$ morphology.

\begin{tabular}{|c|c|c|c|c|c|c|c|}
\hline & \multicolumn{7}{|l|}{ Depth (cm) } \\
\hline & 4 & 10 & 20 & 30 & 40 & 50 & 60 \\
\hline $\begin{array}{l}\text { Normal } \\
\text { Imago } \\
(\%)\end{array}$ & $91.0 \pm 2.5 a$ & $83.0 \pm 1.9 a$ & $55.0 \pm 7.5 a b$ & $24.0 \pm 2.8 \mathrm{ab}$ & $14.0 \pm 1.1 \mathrm{ab}$ & $5.0 \pm 1.0 \mathrm{~b}$ & $0.0 \pm 0.0 \mathrm{~b}$ \\
\hline $\begin{array}{l}\text { Abnormal } \\
\text { Imago } \\
(\%)\end{array}$ & $5.0 \pm 1.0$ & $3.0 \pm 1.0$ & $4.0 \pm 0.0$ & $10.0 \pm 1.1$ & $10.0 \pm 4.7$ & $7.0 \pm 1.9$ & $5.0 \pm 3.7$ \\
\hline
\end{tabular}

It is difficult for the imagoes to come out perfectly, presumably because of the low pore space which limited the imagoes' movement. The depth can also affect the development of the pupa into imago. The other factor is the weight of the soil that covers the pupae. The increases in the soil weight in each treatment cause the decreases in the rate of imago emergence. Soil weight can also be related to soil density, as soil with a finer size will settle to the bottom, which causes compaction. Finally, humidity can also be a factor in the disability of fruit fly imagoes that appear above the ground surface. Abnormal fruit flies are often found in wet soil conditions (Yee, 2013).

\section{Emergence duration of the interspecific hybrid imago

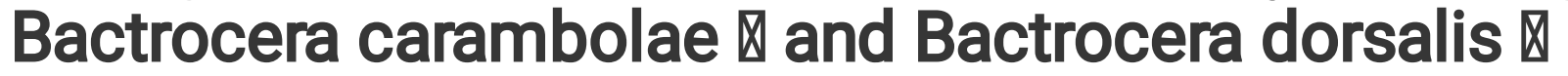

The interspecific mating hybrids of $B$. carambolae and $B$. dorsalis began to appear on the 10th day after formation, or the 8th day after treatment (Table 2$)$. All treatment showed not significantly different $\left(X^{2}=10.66\right.$, $d f=6, p=0.099$ ). 
Table 2

The number of interspecific hybrid imago $B$. carambolae $\Downarrow$ and $B$. dorsalis $\bowtie$ appeared on different days.

\begin{tabular}{|ll|}
\hline Treatment $(\mathbf{c m})$ & Development Time (Day) \\
\hline 4 (Control) & $8.99 \pm 0.10$ \\
10 & $8.90 \pm 0.05$ \\
20 & $8.88 \pm 0.14$ \\
30 & $9.13 \pm 0.23$ \\
40 & $9.18 \pm 0.33$ \\
50 & $10.17 \pm 0.22$ \\
60 & $5.31 \pm 3.07$ \\
\hline Note Day after treatment
\end{tabular}

The depth of pupation influences the duration of pupae development. The interspecific hybrid of $B$. carambolae and $B$. dorsalis took 10-12 days to develop and it was not different from other species that took 10-12 days to develop into imagoes, depending on the depth and other environmental factors (Naik et al., 2017). The highest average occurrence as shown in Figure 3 was on the 11th or 9th day after treatment, while the lowest occurrence was on the 12th or 10th day after treatment. Thus, the optimum time for pupa appearance in the experiment was on the 11th day after pupa formation. Fruit flies are diurnal or insects that are active during the day, and the imagoes generally appear most often in the morning between 06.00 and 12.00 (Shaheta et al., 2008).

Based on the results of the observations in accordance with the statement, the interspecific hybrid imagoes of $B$. carambolae and $B$. dorsalis were not found to emerge in the afternoon. Environmental conditions that are less than optimal can prolong the emergence of fruit fly imago. Larvae prefer to pupate on soil with larger soil particle sizes, making it easier for the new imagoes to emerge from the pupa (Alyokhin et al., 2001). Soil physical properties can affect the emergence of imagoes to the surface by increasing the porosity and decreasing the soil density so that imagoes emerge more easily. It can make it easier for newly emerging imagoes to reach the surface (Hou et al., 2006). In dense soil, it is difficult for imagoes to reach the surface due to the low total pore space of the soil. Therefore, the imagoes took longer to surface than the control.

This research indicate that it is suggested to bury rotten fruit in the soil at a depth of $50 \mathrm{~cm}$ as a preventive measure for the development of fruit flies. Besides, this finding may also be useful to develop the effectiveness of entomopathogenic fungi test related to the depth of the interspecific hybrid $B$. carambolae and $B$. dorsalis. Some soil entomopathogenic fungi such as Metharizium anisopliae isolate cause the high mortality of B. carambolae (Brito et al., 2019). Therefore, the results of this experiment indicates that the pupation depth on adult emergence can be developed so that pupation depth affects the performance of entomopathogenic fungi as the biological control of this fruit fly. 


\section{Declarations}

\section{Conflict of Interest}

The authors declare that there are no conflicts of interest.

\section{References}

1. Amaral, E., Sousa, M., Santos, J., Costa, L., Júnior, N., Toledo, J., Adaime, R. 2021. Effect of soil class and moisture on the depth of pupation and pupal viability of Bactrocera carambolae Drew \& Hancock (1994). Revista Brasileira de Entomologia. 65.

2. Asmare, Dejen \& Hassen, Seid. 2018. Fruit fly damage on orange (Citrus sp.) and Guava (Psidium guajava L.) fruits in Eastern Amhara, Ethiopia. Pp. 2616-471.

3. Bajaj, K., Singh, S. 2020. Preference of Bactrocera spp. to methyl eugenol based different coloured traps. Indian Journal of Agricultural Sciences. 90: 233-235.

4. Brito, B., Lima, A., Cruz, K., Bariani, A., Jesus, C., Pereira, J., Adaime, R. 2019. Amazonian isolates of Metarhizium are effective for killing Bactrocera carambolae (Diptera: Tephritidae). Acta Biológica Colombiana. 24: 118-124.

5. Clarke, A.R. 2019. Biology and management of Bactrocera spp. and related fruit flies. CABI Publishing, Boston.

6. Darwish, D.Y.A., Rizk, M.M.A., Abdel-Galil, F.A., Temerak, S.A.H. 2015. Analysis of factors influencing population density of the peach fruit fly (PFF), Bactrocera zonata (Saunders) (Diptera: Tephritidae) in Assiut, Northern Upper Egypt. Archives of Phytopathology and Plant Protection. 48 (1): 62-72.

7. Djamila, A.A., Soltani, N., Abdellah, K. 2007. Effects of the soil texture and the burying depth of the larvae on some biological parameters of Ceratitis capitata (Diptera: Trypetidae). African Journal of Agricultural Research. 2 (3): 105-111.

8. Drew, R.A.I., Romig, M.C. 2013. Tropical fruit flies of South-East Asia (Tephritidae: Dacinae). Griffith University, Australia.

9. El-Gendy, I.R., AbdAllah, A.M. 2019. Effect of soil type and soil water content levels on pupal mortality of the peach fruit fly Bactrocera zonata (Saunders) (Diptera: Tephritidae). Int. J. Pest Manage. 65: 154-160.

10. Hasyim, A., Setiawati, W., Liferdi, L. 2014. Fruit fly pest control technology on chili plants. IPTEK Hortikultura, Balai Penelitian Tanaman Sayuran, Lembang, Bandung Barat. 10: 20-25.

11. Heriza, S., Himawan, T., Tarno, H, 2013. The use of corn cobs and papaya as raw materials for artificial feed for the development of fruit fly larvae Bactrocera carambolae Drew and Hancock (Diptera:

Tephritidae). HPT. 1(1): 80-89.

12. Hill, M. P., Trullas, S.C., Terblanche, J.S., Richardson, D.M. 2016. Drivers, impacts, mechanisms and adaptation in insect invasions. Biological Invasions, Springer International Publishing, Switzerland.

13. Hou, B., Xie, Q., Zhang, R. 2006. Depth of pupation and survival of the oriental fruit fly, Bactrocera dorsalis (Diptera: Tephritidae) pupae at selected soil moistures. Applied Entomology and Zoology. 41: 515-520. 
14. Juma, S., Muhamad, R., Adam, N.A., Hee, A.K.W., Gnanasegaram, M. 2014. Occurrence of tephritid fruit flies with intermediate morphologies of Bactrocera carambolae and B. papayae (Diptera: Tephritidae) in Selangor, peninsular Malaysia. Australian Journal of Basic and Applied Sciences. 8 (17): 609-616.

15. Kago, H., Sawada, H., Susanto, A., Takakura, K., Nishida, T., Tsukada M. 2012. A simple criterion for distinguishing between sympatric fruiy flies Bactrocera carambolae and B. papayae(Diptera : Tephritidae) notorious pests of diverse fruits on Java. Japanese Journal of Environmental Entomology and Zoology. 23 (3): 143-149.

16. Klungness, L.M., Jang, E.B., Mau, R.F.L., Vargas, R.I., Sugano, J.S., Fujitani, E. 2005. New approaches to sanitation in a cropping system susceptible to tephritid fruit flies (Diptera: Tephritidae) in Hawaii. Journal of Applied Science and Environmental Management, 9: 5-15.

17. Li, Z., Chambi, C., Du, T., Huang, C., Wang, F., Zhang, G., Li, C., Kayeke, J. 2019. Effects of water immersion and soil moisture content on larval and pupal survival of Bactrocera minax (Diptera: Tephritidae). Insects. 10(5): 138.

18. Mir, S., Dar, S., Mir, G., Ahmad, S. 2014. Biology of Bactrocera cucurbitae (Diptera: Tephritidae) on cucumber. Florida Entomologist. 97: 753-758.

19. Naik, H.S., Jagadeesh, K.S., Basavaraju, B.S. 2017. Biology and biometric of oriental fruit fly, Bactrocera dorsalis (Hendel) (Diptera: Tephritidae) on custard apple, Annona squamosa L. International Journal of Current Microbiology and Applied Science. 6 (12): 3859-3864.

20. Okuyama, T. 2019. Concurrently burrowing host fly larvae reciprocally enhance pupation depth to minimise parasitism risk. Ecological Entomology. 45 (3): 493-497.

21. Pilania, S., Singh, S., Rolania, K., Kumar, R., Indora, J., Kaushik, A. 2021. Assessment of avoidable yield losses in bitter gourd due to melon fruit fly, Bactrocera cucurbitae (Coquillett). Journal of Entomology and Zoology Studies. 9 (2): 396-398.

22. Schutze, M.K., Jessup, A., Ul-Haq, I., Vreysen, M.J.B., Wornoayporn, V., Vera, M.T., Clarke, A.R. 2013. Mating compatibility among four pest members of the Bactrocera dorsalis fruit fly species complex (Diptera: Tephritidae). J. Econ. Entomol. 106 (2): 695-707.

23. Shaheta, N.F., Younnes, M.W.F., Mahmoud, Y.A. 2008. Biological studies on the peach fruit fly, Bactrocera zonata (Saunders) in Egypt. Journal of Applied Science Research. 4 (9): 1103-1106.

24. Susanto, A., Sudarjat, S., Yulia, E., Permana, A., Gunawan, A., Yudistira, D.H. 2020. Effectiveness of Modified Traps for Protection Against Fruit Flies on Mango. Jurnal Biodjati. 5 (1): 99-106.

25. Susanto, A., Nasahi, C., Rumaisha, Y., Murdita, W., Lestari, T. 2019. Addition of Fruit Essence on the Effectiveness of Methyl Eugenol in Attracting Bactrocera spp. Drew \& Hancock. Agrikultura. 30 (2): 53-62.

26. Wee, S.L., Tan, K.H. 2005. Evidence of natural hybridization between two sympatric sibling species of Bactrocera dorsalis complex based on pheromone analysis. Journal of Chemical Ecology. 31 (4): 845 858.

27. Yee, W. 2013. Soil moisture and relative humidity effects during postdiapause on the emergence of western cherry fruit fly (Diptera: Tephritidae). The Canadian Entomologist. 145 (3): 317-326.

\section{Figures}




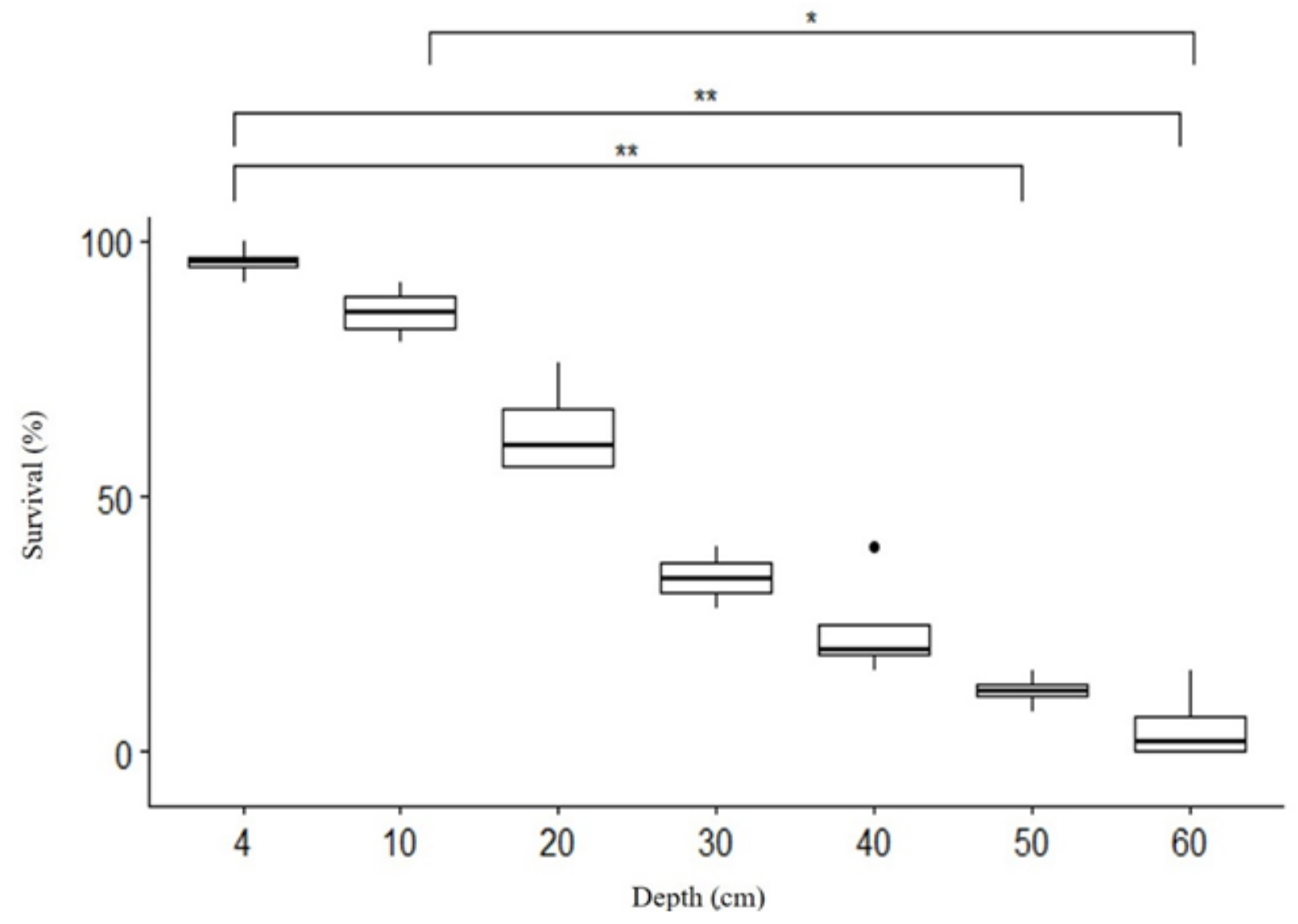

Figure 1

Boxplot of effect of soil depth on interspecific hybrid B. carambolae $\nabla$ and B. dorsalis $\nabla$ adult emergence. Star sign (*) indicate significant differences at the level of $\mathrm{P}<0.05$ (Bonferroni). 


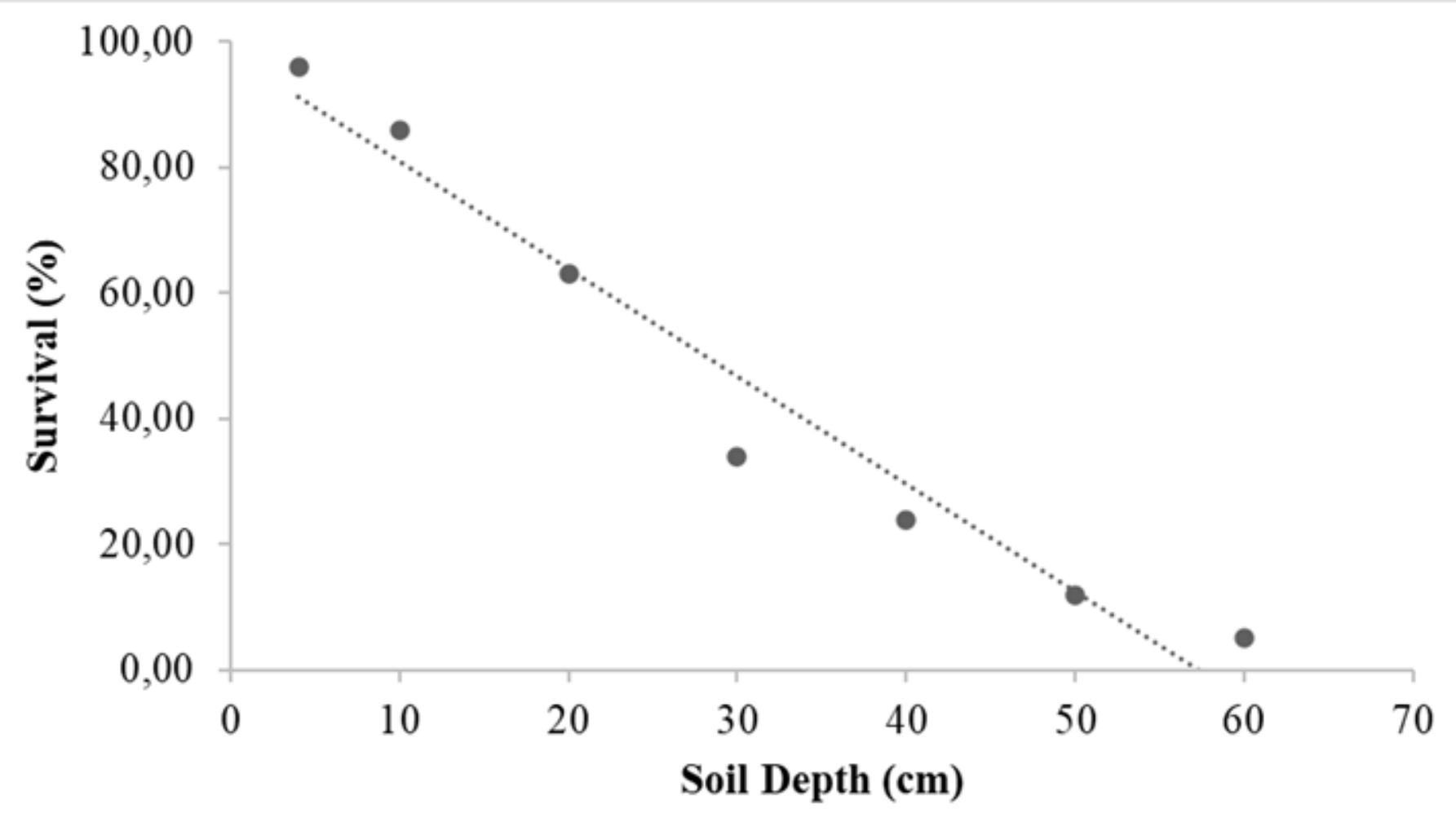

Figure 2

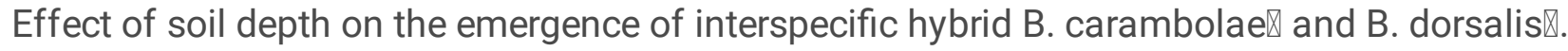
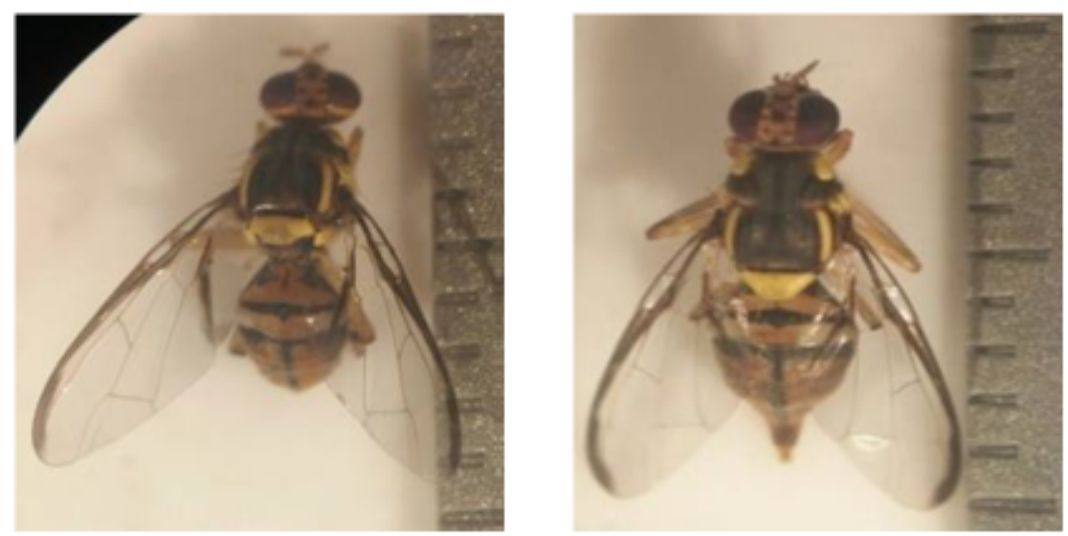

Figure 3

Normal male (left) and female (right) imago hybrids morphology. 

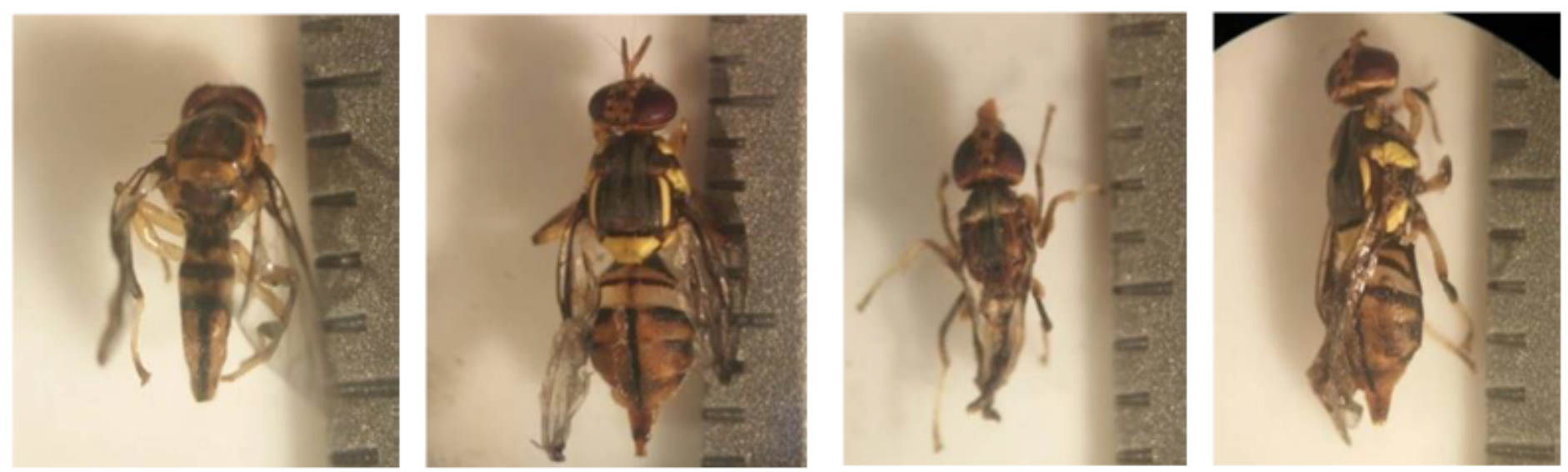

Figure 4

Abnormal imago caused by the pupation depth $(30-60 \mathrm{~cm})$. 